\title{
ECG Waveforms Not Present
}

National Cancer Institute

\section{Source}

National Cancer Institute. ECG Waveforms Not Present. NCI Thesaurus. Code C114163.

An electrocardiographic recording that displays flat lines (no waveforms are visible) in all leads present. (CDISC) 